\title{
Herdabilidade para Efeitos Direto e Materno de Características de Crescimento de Bovinos Nelore no Estado da Paraíba ${ }^{1}$
}

\author{
Maria Norma Ribeiro2, Edgard Cavalcanti Pimenta Filho3,4, Gabrimar Araújo Martins4, \\ José Lindenberg Rocha Sarmento ${ }^{4,5}$, Raimundo Martins Filho 4,6
}

\begin{abstract}
RESUMO - Dados de pesos aos 205 (P205), 365 (P365) e 550 dias de idade (P550) de três rebanhos da raça Nelore criados no Estado da Paraíba em regime de pasto, no período de 1975 a 1990, foram utilizados. Os efeitos genéticos direto e materno foram estimados pelo Método da Máxima Verossimilhança Restrita aplicada a um modelo animal. Foram incluídos os efeitos fixos de ano-mês-sexo, fazenda e idade da vaca, como (co) variável linear e quadrática. As médias dos quadrados mínimos e respectivos erros-padrão dos P205, P365 e P550 para as três propriedades estudadas foram, respectivamente, $149,00 \pm 22,28 \mathrm{~kg}, 198,40 \pm 38,84 \mathrm{~kg}, 256,99 \pm 55,65 \mathrm{~kg} ; 145,10$ $\pm 21,31 \mathrm{~kg}, 182,83 \pm 30,38 \mathrm{~kg}, 247,45 \pm 50,57 \mathrm{~kg}$ e $162,12 \pm 14,23 \mathrm{~kg}, 246,66 \pm 23,11 \mathrm{~kg}, 332,83 \pm 35,02 \mathrm{~kg}$. As estimativas de herdabilidade para o efeito genético direto dos pesos aos 205,365 e 550 dias de idade foram $0,16 \pm 0,05,0,40 \pm 0,11$ e $0,76 \pm 0,25$, respectivamente. Nesta mesma ordem, para o efeito materno dos P205, P365 e P550, os valores de herdabilidade foram 0,36 $\pm 0,05,0,44 \pm 0,15$ e $0,01 \pm 1,10$. As correlações para os efeitos genético direto e materno para P205, P365 e P550 foram, respectivamente $-0,70,-0,74$, e $-1,00$. O efeito materno foi importante apenas na fase pré-desmame.
\end{abstract}

Palavras-chave: peso à desmama, pesos pós-desmama, Nelore

\section{Heritability of Maternal and Direct Effects of Growth Traits in Nellore Herds at Paraiba State, Brazil}

\begin{abstract}
Weight records at 205 (205W), 365 (365W) and 550 (550W) days of age of three Nellore herds raised in Paraíba State from 1975 to 1990, were used in the analyses. Genetic and maternal effects were estimated with the restricted maximum likelihood method, assuming an animal model. There were included the fixed effects of year-month-sex and farm. The linear and quadratic effects of age of dam at calving were included in the model as covariables. The least squares means and respective standard errors for P205, P365 and P550 for three studied farms were, respectively, $149.00 \pm 22.28 \mathrm{~kg}, 198.40 \pm 38.84 \mathrm{~kg}, 256.99 \pm 55.65 \mathrm{~kg} ; 145.10 \pm 21.31 \mathrm{~kg}, 182.83$ $\pm 30.38 \mathrm{~kg}, 247.45 \pm 50.57 \mathrm{~kg}$ e $162.12 \pm 14.23 \mathrm{~kg}, 246.66 \pm 23.11 \mathrm{~kg}, 332.83 \pm 35.02 \mathrm{~kg}$. The heritabilities estimates for genetic direct effect were $0,16 \pm 0,05,0,40 \pm 0,11$ e $0,76 \pm 0,25$, for $205 \mathrm{~W}, 365 \mathrm{~W}$ and $550 \mathrm{~W}$, respectively. The heritabilities estimated for the maternal effects of $205 \mathrm{~W}, 365 \mathrm{~W}$ and $550 \mathrm{~W}$ were $0,36 \pm 0,05,0,44 \pm 0,15$ and $0,01 \pm 1,10$, respectively. The correlations between direct and maternal effect for $205 \mathrm{~W}, 365 \mathrm{~W}$ and $550 \mathrm{~W}$ were $-0,70,-0,74$, and $-1,00$, respectively. Maternal effects were important only in the pre-weaning phase.
\end{abstract}

Key Words: growth, genetic parameters, Nellore cattle

\section{Introdução}

As características fenotípicas de valor econômico são influenciadas por um componente genotípico que inclui a variância genética aditiva e não aditiva dos genes e um componente ambiental, regulado pela influência temporária ou permanente do meio ambiente. $\mathrm{O}$ ambiente materno pode influenciar o crescimento do bezerro tanto na fase pré-natal quanto na fase pósnatal, sendo que nesta última a influência materna estará em maior dependência do manejo empregado. A metodologia REML constitui-se em ferramenta eficaz para estudar o efeito materno, pois possibilita obter-se separadamente o componente de variância do próprio indivíduo e o componente devido ao efeito materno, através da utilização de informações dos parentes do animal (BOLDMAN et al., 1995). WILHAM (1972), discutindo aspectos do efeito materno sobre o desempenho de mamíferos domésticos, destaca a importância da relação de parentesco

\footnotetext{
1 Trabalho financiado pelo CNPq - processo no 521157/97-8.

2 Professora da Universidade Federal Rural de Pernambuco/DZ - Recife-PE . E-mail: mnribeiro@yahoo.com

3 Professor da Universidade Federal da Paraíba/CCA/DZ, CAMPUS III - Areia-PB.

${ }^{4}$ Bolsistas do CNPq.

${ }^{5}$ Bolsistas do Iniciação Científica, acadêmico de Zootecnia da UFPB.

6 Professor da Universidade Federal do Ceará/CCA/DZ - Fortaleza-CE.
} 
entre os membros da família como, por exemplo, a influência da mãe e, possivelmente, da avó materna do bezerro.

MEYER et al. (1993), estudando bovinos Hereford puros e cruzados, na Austrália, observaram efeito materno sobre o crescimento até os 365 dias de idade, sugerindo que relações adversas entre o crescimento do bezerro e o desempenho da vaca se devem à diferenças de meio ambiente e manejo, resultando em covariância negativa atribuída à mãe do bezerro, fato também comprovado por GARNERO et al. (1998).

Os objetivos deste trabalho foram estimar as herdabilidades para os efeitos genéticos direto e materno dos pesos aos 205, 365 e 550 dias de idade de bovinos da raça Nelore criados no Estado da Paraíba.

\section{Material e Métodos}

Os dados utilizados no presente estudo foram provenientes de três rebanhos criados a pasto no Estado da Paraíba, submetidos ao Controle de Desenvolvimento Ponderal (CDP) realizado pela Associação Brasileira de Criadores de Zebu (ABCZ).

Foram utilizados para análise dados de touros com mais de seis filhos em cada rebanho e grupo ano-mêssexo com um mínimo de três animais. Foram eliminados todos os dados atípicos para idade da mãe e pesos, de forma que foram mantidos 5.463 pesos aos 205 , 3.836 pesos aos 365 e 1.045 pesos aos 550 dias de idade, de animais nascidos no período de 1975 a 1990.

O manejo alimentar era realizado de acordo com a estação do ano (chuvosa ou seca). Na estação chuvosa os animais eram criados em regime exclusivo de pasto e, na estação seca, recebiam suplementação volumosa à base de capim elefante (Penissetum purpureum Schum.) e sal mineral à vontade durante todo o ano.

As análises estatísticas foram feitas no Setor de Melhoramento Animal do Departamento de Zootecnia da Universidade Federal da Paraíba. Utilizou-se o método da máxima verossimilhança restrita aplicado a um modelo animal, usando o programa MTDFREML desenvolvido por BOLDMAN et al. (1995), segundo o modelo:

$$
\mathrm{Y}=\mathrm{X} \beta+\mathrm{Z}_{1} \mathrm{a}+\mathrm{Z}_{2} \mu+\mathrm{e}
$$

em que: $Y=$ vetor das observações (P205, P365 e P550 dias de idade); $\mathrm{X}=$ matriz de incidência dos efeitos fixos (ano-mês-sexo, fazenda e idade da mãe); $\beta=$ vetor dos efeitos fixos (ano-mês-sexo, fazenda e idade da mãe) $Z_{1}=$ matriz de incidência dos efeitos genéticos diretos; $\mathrm{a}=$ vetor de efeitos genéticos diretos do animal; $Z_{2}=$ matriz de incidência dos efeitos genéticos maternos; $\mu=$ vetor de efeitos genéticos maternos; e = vetor dos erros aleatórios associados às observações.

\section{Resultados e Discussão}

As médias e respectivos erros-padrão dos pesos aos 205, 365 e P550 dias de idade para as três propriedades estudadas foram, respectivamente, $149,00 \pm 22,28 \mathrm{~kg}, 198,40 \pm 38,84 \mathrm{~kg}, 256,99 \pm 55,65$ $\mathrm{kg} ; 145,10 \pm 21,31 \mathrm{~kg}, 182,83 \pm 30,38 \mathrm{~kg}, 247,45 \pm$ $50,57 \mathrm{~kg}$ e $162,12 \pm 14,23 \mathrm{~kg}, 246,66 \pm 23,11 \mathrm{~kg}, 332,83$ $\pm 35,02 \mathrm{~kg}$. Os resultados da análise de variância são apresentados na Tabela 1. Todos os efeitos foram significativos $(\mathrm{P}<0,001)$, exceto o efeito de fazenda para $\mathrm{P} 205$ e $\mathrm{P} 365$, resultado contrário ao obtido por BIFFANI et al. (1999). O efeito significativo do anomês-sexo indica que as condições climáticas da região, o manejo adotado e o dimorfismo sexual dos animais contribuíram para as diferenças nos pesos obtidos. A idade da vaca ao parto, também teve uma contribuição importante sobre os pesos estudados em todas as fases de crescimento (Tabela 1), ao contrário dos resultados obtidos por MARTINS FILHO et al. (1997), para pesos aos 365 e 550 dias de idade e, por BIFFANI et al. (1999), para peso aos 550 dias de idade nesta mesma raça nos Estados do Ceará e Maranhão.

BARBOSA et al. (1999), estimaram a herdabilidade do peso aos 550 dias de idade em rebanhos Nelore no Estado de Pernambuco e também obtiveram valores bastante elevados para esta característica. Estes resultados sugerem que é possível obter-se ganhos genéticos bastante expressivos na raça Nelore para características de crescimento, por seleção massal.

As variâncias aditivas para os efeitos direto e materno, a (co) variância entre efeito direto e materno, os coeficientes de herdabilidade para efeito direto e materno e as correlações entre efeito direto e materno, para as características estudadas, são apresentadas na Tabela 2. Os valores estimados para a variância genética aditiva direta foram de magnitude mediana, indicando que os rebanhos da raça Nelore da Paraíba apresentam variabilidade genética que pode ser explorada por seleção. Uma seleção intensa pode resultar em melhoria no desempenho médio da população e, conseqüentemente, promover progresso genético nas características de crescimento ao longo dos anos. 
1226 Rev. bras. zootec.

Tabela 1 - Resumo da análise de variância para os pesos aos 205 (P205), 365 (P365) e 550 dias de idade (P550)

Table 1 - Summary of the analysis of variance for weights at 205 (205W), 365 (365W) and 550 days of age (550W)

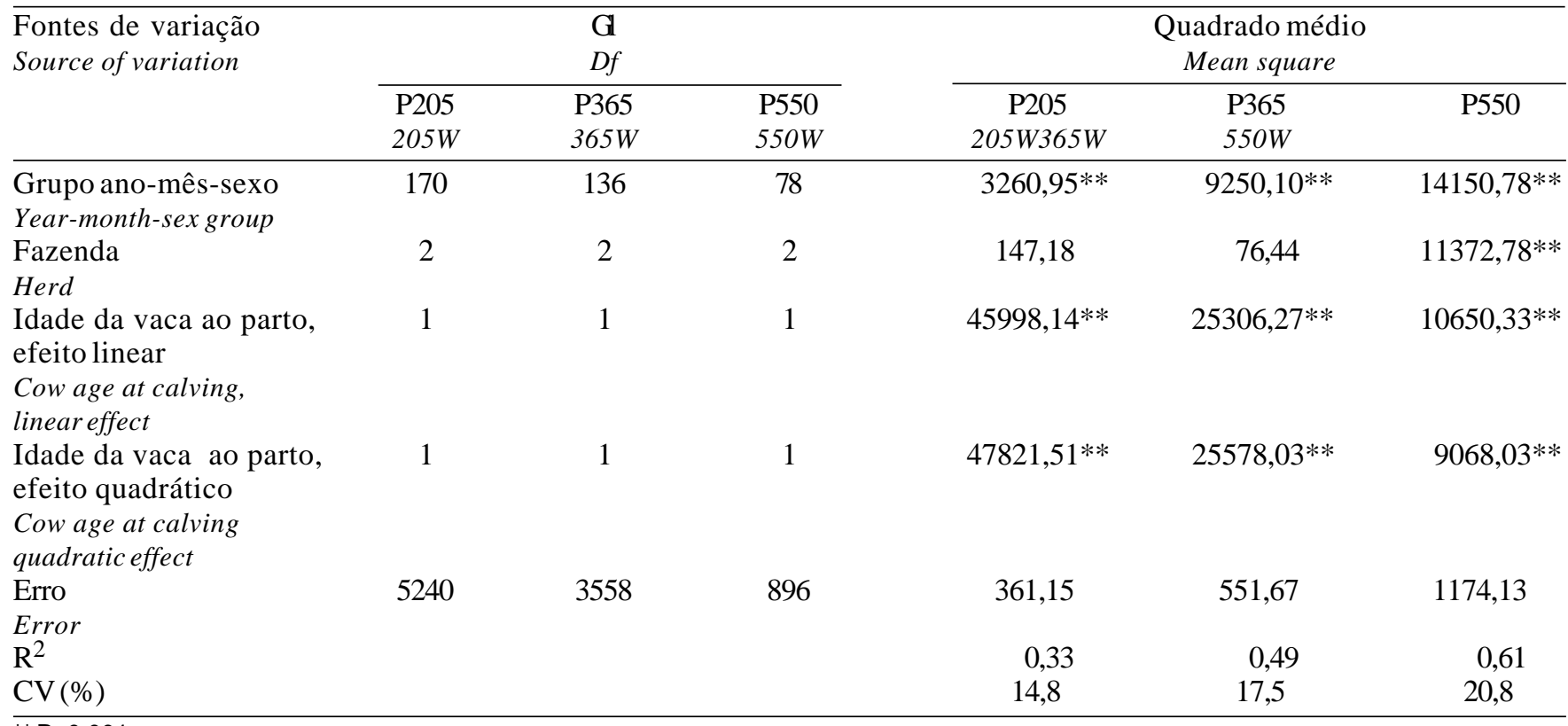

${ }^{\star *} \mathrm{P}<0,001$.

A estimativa de herdabilidade do efeito genético aditivo direto foi baixa para o peso aos 205 dias de idade. Nesta fase o efeito materno teve maior influência, fato esperado, uma vez que nesta fase, existe maior dependência dos bezerros em relação às suas mães. Este efeito tende a diminuir com o passar do tempo, sendo mínimo aos 550 dias de idade.

Na Tabela 2, observa-se que a estimativa de herdabilidade do peso aos 550 dias de idade para o efeito genético direto foi alta $(0,76)$ e para o efeito genético materno foi muito baixa $(0,01)$, comprovando a pequena dependência dos bezerros em relação às suas mães nesta fase. Isto sugere que a variação fenotípica total para o peso aos 550 dias de idade depende, em grande proporção, do efeito genético aditivo direto. Este fato é comprovado pelos valores altos e negativos das correlações entre os efeitos genéticos aditivo direto e materno dos pesos estudados (Tabela 2), que segundo MAYER et al. (1993) e GARNERO et al. (1998), é promovido pelo antagonismo entre os efeitos dos genes para potencial de crescimento e habilidade materna.

A magnitude da contribuição do efeito materno na variação fenotípica total para os pesos aos 205 e 365 dias de idade, indica que há necessidade de sua inclusão no modelo para se obter estimativas dos parâmetros genéticos para estes pesos com maior acurácia.

BIFFANI et al. (1999), utilizaram um modelo touro para estimar herdabilidade dos pesos aos $365 \mathrm{e}$ 550 dias de idade em rebanhos Nelore nos estados do Ceará e Maranhão, obtendo resultados próximos aos encontrados neste trabalho.

Tabela 2 - Estimativas dos componentes das variâncias genética $\left(\mathrm{s}^{2} \mathrm{~A}\right)$, materna $\left(\mathrm{s}^{2} \mathrm{M}\right)$, covariância e parâmetros genéticos dos pesos aos 205 (P205), 365 (P365) e 550 (P550) dias de idade

Table 2 - Estimates of genetic $\left(s^{2}{ }_{A}\right)$, and maternal $\left(s^{2}{ }_{M}\right)$ variances and genetic-maternal covariances and parameters of $205 \mathrm{~W}, 365 \mathrm{~W}$ and $550 W$ days old

\begin{tabular}{lcccccc}
\hline $\begin{array}{l}\text { Características } \\
\text { Traits }\end{array}$ & $\sigma^{2}{ }_{\mathrm{A}}$ & $\sigma^{2}{ }_{\mathrm{M}}$ & $\mathrm{Cov}_{\mathrm{AM}}$ & $\mathrm{h}^{2}{ }_{\mathrm{A}}$ & $\mathrm{h}^{2}{ }_{\mathrm{M}}$ & $\mathrm{r}_{\mathrm{AM}}$ \\
\hline P205 $(205 \mathrm{~W})$ & 54,87 & 120,60 & $-57,04$ & $0,16 \pm 0,05$ & $0,36 \pm 0,08$ & $-0,70$ \\
P365 $(365 \mathrm{~W})$ & 258,0 & 285,3 & $-201,7$ & $0,40 \pm 0,10$ & $0,44 \pm 0,15$ & $-0,74$ \\
P550 $(550 \mathrm{~W})$ & 1177,7 & 15,1 & $-133,4$ & $0,76 \pm 0,24$ & $0,01 \pm 1,1$ & $-1,0$ \\
\hline
\end{tabular}

$\sigma^{2}$ : variância genética aditiva direta, $\sigma^{2}$ : variância genética aditiva materna, $\operatorname{Cov}_{\mathrm{AM}}:$ covariância entre efeito direto e materno, $\mathrm{h}_{\mathrm{A}}^{2}:$ herdabilidade para efeito direto, $\mathrm{h}^{2} \mathrm{M}$ : herdabilidade para efeito materno, $\mathrm{r}_{\mathrm{AM}}$ : correlação entre efeito direto e materno.

$\sigma_{A}^{2}$ : direct additive genetic variance, $\sigma_{M}^{2}$ : maternal genetic variance, $\operatorname{Cov}_{A M}$ : direct and maternal covariance, $h^{2}{ }_{A}$ : direct heritability, $h^{2}$ : maternal heritability, $r_{A M}$ : direct and maternal correlation. 


\section{Conclusões}

A variação genética aditiva para as características estudadas foi relativamente alta, podendo-se obter ganhos genéticos por seleção, principalmente na fase pós-desmama, pela maior contribuição do efeito genético direto nessa fase.

O efeito materno deve ser incluído nos modelos para avaliação genética até um ano de idade, uma vez que teve participação expressiva nessa fase.

\section{Referências Bibliográficas}

BARBOSA, S.B.P., MARTINS FILHO, R., MARTINS, G.A. et al. Aspectos genéticos e de ambiente em características de crescimento em bovinos de raça Nelore, no Estado de Pernambuco. In: REUNIÃO ANUAL DA SOCIEDADE BRASILEIRA DE ZOOTECNIA, 36, 1999, Porto Alegre, RS. Anais... Porto Alegre, 1999. p.147.

BIFFANI, S., MARTINS FILHO, R., MARTINI, A. et al. 1999. Fatores ambientais e genéticos sobre o crescimento ao ano e ao sobreano de bovinos Nelore, criados no nordeste do Brasil. R. Soc. Bras. Zootec., 28(3):468-472.

BOLDMAN, K.G., KRIESE, L.A., VAN VLECK, L.D. et al.1995. A manual for use of MTDFREML; a set of programs to obtain estimates of variance and (co)variance (DRAFT). Lincoln: Department of Agriculture/Agriculture Research Service. 120 p.
GARNERO, A.V., LÔBO, R.B., BORJAS, A.R. et. al. Estimativas de parâmetros genéticos para características incluídas em critérios de seleção em gado de corte. In: REUNIÃO ANUAL DA SOCIEDADE BRASILEIRA DE ZOOTECNIA, 35, 1998, Botucatu, SP. Anais... Botucatu, 1998. p.434-436.

MARTINS FILHO, R., LÔBO, R.N.B., LIMA, F.A.M. et al. Parâmetros genéticos e fenotípicos de pesos e ganhos em pesos de bovinos zebus no Estado do Ceará. In: REUNIÃO ANUAL DA SOCIEDADE BRASILEIRA DE ZOOTECNIA, 34, 1997, Juiz de Fora, MG. Anais... Juiz de Fora, 1997. p.248-250.

MEYER, K., CARRICK, M.J., DONNELLY, B.J.P. 1993. Genetic parameters for growth traits of Australian beef cattle from a multbreed selection experiment. J. Anim. Sci., 71:2614-2622.

WILHAM, R.L. 1972. The role of maternal effects in animal breeding: III. Biometrical aspects maternal effects in animals. J. Anim. Sci., 35:1288-1293.

Recebido em: 04/02/00

Aceito em: 18/05/01 